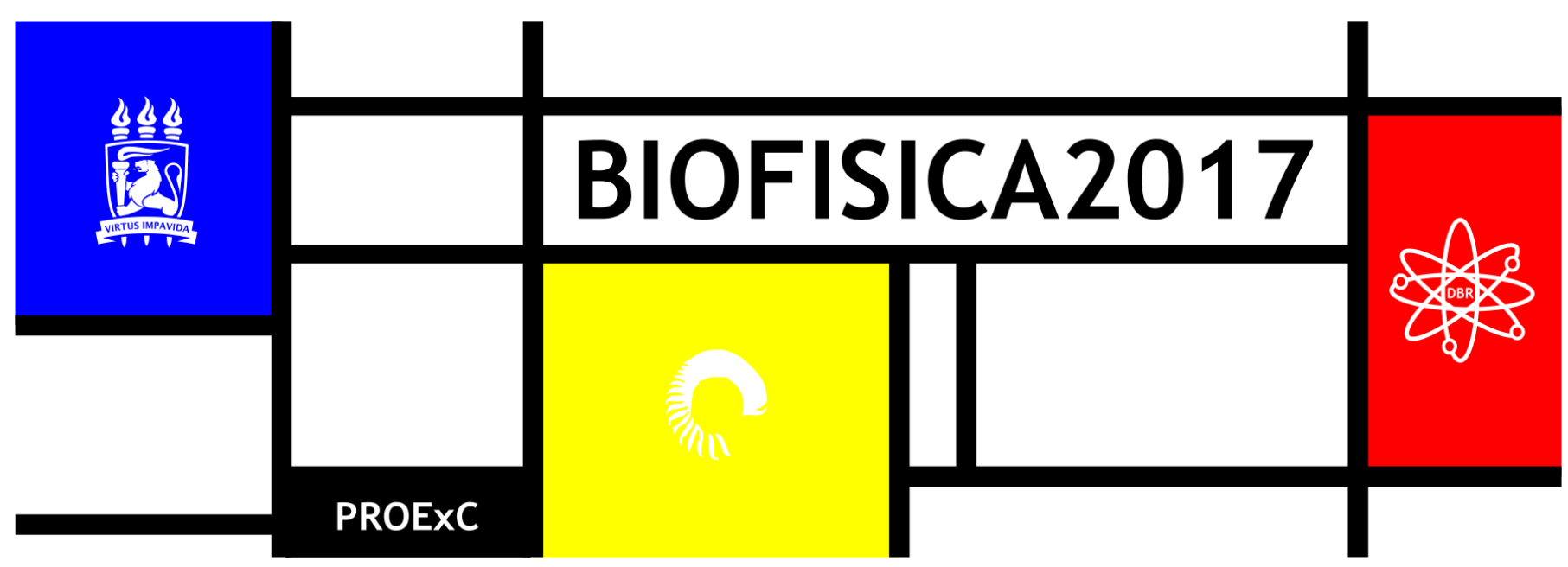

\title{
QUANTUM DOTS CONJUGADOS AO ÁCIDO FÓLICO PARA MARCAÇÃO DE RECEPTORES EM CÉLULAS CANCERÍGENAS
}

\author{
Camila A. P. Monteiro ${ }^{1}$, Ryan C. Silva ${ }^{1 *}$, Goreti Pereira ${ }^{2}$, Aline D. P. R. Oliveira ${ }^{1}$, Beate S. Santos ${ }^{3}$, Giovannia A. L. \\ Pereira ${ }^{2}$, Paulo E. Cabral Filho ${ }^{1}$, Adriana Fontes ${ }^{1}$ \\ 1Departamento de Biofísica e Radiobiologia, UFPE; ²Departamento de Química Fundamental, UFPE; ${ }^{3}$ Departamento de Ciências Farmacêuticas, \\ UFPE. \\ *ryanc.silva5@gmail.com
}

\section{INTRODUÇÃO}

O ácido fólico (AF) é uma vitamina de origem exógena, solúvel em água, pertencente ao complexo do grupo B (CHEUNG et al., 2008), e como todas as outras vitaminas, regula atividades metabólicas essenciais no desenvolvimento do corpo humano. A baixa ou inadequada ingestão de AF é associada ao aumento de risco de diversas patologias, incluindo defeitos no tubo neural fetal, doenças cardiovasculares e do câncer (CHEN et al., 2013). Seu receptor, o receptor de folato (RF), geralmente apresenta uma superexpressão em superfícies de várias células tumorais humanas, como do cérebro, rim, ovário e mama (WANG \& LOW, 1998). Sendo assim, o AF pode ser facilmente internalizado via RF pelas células cancerígenas, podendo se tornar uma ferramenta para um diagnóstico mais rápido e eficiente, bem como para ajudar a aumentar a eficácia de quimioterápicos, além de fornecer um melhor entendimento da biologia celular do câncer. A conjugação do $\mathrm{AF}$ a substâncias fluorescentes é uma chave estratégica para estudar e quantificar os RFs em células cancerígenas (LEl et al., 2016). As técnicas baseadas em fluorescência possuem alta sensibilidade e especificidade e vem sendo utilizadas para quantificar e localizar dentro do ambiente celular diversos tipos de moléculas (CABRAL FILHO et al., 2016), como a internalização e o tráfego do RF no citoplasma das células.

Os quantum dots (QDs) constituem uma nova classe de sondas fluorescentes que vem sendo bastante aplicada em biomedicina. Os QDs são nanocristais fluorescentes que apresentam propriedades únicas, tais como: excelente resistência à fotodegradação (podendo ser manuseados à luz ambiente, possibilitando a aquisição de eventos celulares em tempo real e por longos períodos), além disso, eles possuem superfície ativa para conjugações a biomoléculas, podendo identificar/traçar moléculas alvo específicas na membrana celular, tais como os receptores (KAIRDOLF et al., 2013; ESTEVE-TURRILLAS \& ABAD-FUENTES, 2013).
Dentro desse contexto, utilizando-se da versatilidade dessas novas nanossondas, este trabalho teve como objetivo padronizar a conjugação de QDs de CdTe ao ácido fólico e demonstrar sua atuação para marcação de células cancerígenas. Portanto, o desenvolvimento dessas nanossondas tem potencial para contribuir para o melhor entendimento da biologia celular do câncer, podendo assim auxiliar no seu diagnóstico e no desenvolvimento de novas formas terapêuticas.

\section{MATERIAIS E MÉTODOS}

\section{Síntese e caracterização dos QDs}

A síntese dos QDs de telureto de cádmio (CdTe) em meio aquoso foi adaptada da metodologia já descrita por Cabral Filho et al. (2016). O processo de síntese é didaticamente dividido em duas etapas: em uma primeira etapa, prepara-se uma solução de $\mathrm{Cd}^{2+} / \mathrm{AMS}$, formada a partir dos precursores de cádmio $\left(\mathrm{CdCl}_{2}\right.$ a 0,5 $\mathrm{mmol}$ ) e do agente funcionalizante/estabilizante da reação, o ácido mercaptossuccínico (AMS 0,6 mmol), em $\mathrm{pH}$ de aproximadamente 10,5, ajustado com $\mathrm{NaOH}\left(2 \mathrm{~mol} . \mathrm{L}^{-1}\right)$. Na segunda etapa, simultânea à primeira, ocorre a redução do telúrio $(0,1 \mathrm{mmol})$, por ação do agente redutor, o boridreto de sódio $\left(\mathrm{NaBH}_{4}, 3 \mathrm{mmol}\right)$, sob atmosfera inerte e em pH básico, sendo a redução evidenciada pela mudança da coloração de violeta $\left(\mathrm{Te}^{1-}\right)$ para o transparente $\left(\mathrm{Te}^{2-}\right)$. Posteriormente, o $\mathrm{Te}^{2-}$ é adicionado na solução de $\mathrm{Cd}^{2+} / \mathrm{AMS}$ para formação das nanopartículas, permanecendo por 8 horas, sob agitação e refluxo $\left(90-100{ }^{\circ} \mathrm{C}\right)$, tendo uma proporção molar de 5:1:6 ( $\left.\mathrm{Cd}^{2+}: \mathrm{Te}^{2}: \mathrm{AMS}\right)$.

As caracterizações ópticas dos QDs foram obtidas através da aquisição de espectros de absorção e emissão, utilizando, respectivamente, o espectrofotômetro UV-Vis 1800 (Shimadzu) e o espectrofluorímetro LS55 (PerkinElmer).

Bioconjugação dos QDs ao ácido fólico

QDs de CdTe funcionalizados/estabilizados com o AMS foram conjugados ao ácido fólico (AF), para a investigação dos receptores 
de folato nas células tumorais HeLa. Foram testadas 5 variações entre concentrações de QDs, N-etil-3-(3-dimetilaminopropil) carbodiimida (EDC) e $\mathrm{N}$-hidroxisulfosuccinimida (Sulfo-NHS), além de proporções QDs-AF, como podem ser vistas na Tabela 1. A cada tentativa de conjugação foi avaliada a estabilidade coloidal e manutenção da fluorescência.

Para a conjugação, os QDs tiveram o pH ajustado com AMS (4,9\%) para próximo de 5,5, posteriormente foram feitas 3 lavagens sucessivas das suspensões dos QDs, por meio de centrifugação, a $3000 \mathrm{rpm}$ (Hettich Zentrifugen - Universal 320 R) por $3 \mathrm{~min}$, utilizando tubos de separação com membranas de $10 \mathrm{KDa}$ (GE Healthcare), para remover os resíduos da síntese, que pudessem interferir nas conjugações. Em seguida, os QDs foram ressuspendidos em água ultrapura, até atingir as concentrações indicadas na Tabela 1.

Para favorecer a conjugação covalente dos QDs ao ácido fólico, os grupos carboxílicos presentes nas nanopartículas foram ativados com agentes de acoplamento, EDC e Sulfo-NHS. Por fim, foi adicionado o ácido fólico (Tabela 1 ). A reação permaneceu sob agitação overnight em temperatura ambiente. Ao final, os conjugados foram armazenados na geladeira por 7 dias para futuras análises.

Tabela 1. Combinações testadas para a conjugação QDs-AF.

\begin{tabular}{ccccc}
\hline Variações & QDs $(\boldsymbol{\mu M})$ & EDC $(\mathbf{m M})$ & Sulfo-NHS $(\mathbf{m M})$ & QD:AF \\
\hline $\mathbf{1}$ & 5,7 & 2 & 5 & $1: 5$ \\
$\mathbf{2}$ & 5,7 & 20 & 25 & $1: 5$ \\
$\mathbf{3}$ & 0,8 & 20 & 25 & $1: 10$ \\
$\mathbf{4}$ & 3 & 2 & 5 & $1: 25$ \\
$\mathbf{5}$ & 3 & 2 & 5 & $1: 50$ \\
\hline
\end{tabular}

\section{Cultura celular}

As células HeLa (carcinoma de células epiteliais humana) foram cultivadas em DMEM (Dulbecco's modified Eagle's medium) com alta quantidade de glicose, suplementado com $10 \%$ de soro fetal bovino (FBS), $100 \mathrm{mg} / \mathrm{mL}$ de estreptomicina e 100 unidades $/ \mathrm{mL}$ de penicilina (Sigma Aldrich), mantidas na estufa a $37{ }^{\circ} \mathrm{C}$, em atmosfera umidificada e com $5 \%$ de $\mathrm{CO}_{2}$. Quando as células atingiram 80 - 90\% de confluência na garrafa foi feito a tripsinização, contagem e plaqueamento utilizando $5,0 \times 10^{4}$ células/poço, as quais permaneceram na estufa por 24 horas.

\section{Marcação celular utilizando QDs-AF}

Para marcação celular o conjugado QDs-AF teve inicialmente os grupamentos carboxílicos bloqueados com TRIS base $\left(1 \mathrm{mmol}^{-\mathrm{L}^{-1}}\right)$ por $2 \mathrm{~h}$, sob agitação para minimizar eventuais marcações inespecíficas.

As células foram lavadas com PBS $1 \mathrm{X}$ e incubadas com conjugado bloqueado também em PBS $1 X$ na proporção de $1: 2 \mathrm{v} / \mathrm{v}$, por 40 min. Após este período foram feitas sucessivas lavagens e, por fim as células foram incubadas com um marcador para núcleo, o Hoescht $(0,6 \mu \mathrm{g} / \mathrm{mL})$, por 5 min e seguida foram realizadas mais duas lavagens utilizando PBS $1 \mathrm{X}$. Após as lavagens, as células foram analisadas em um microscópio de fluorescência (Leica DMI4000B), utilizando o filtro de excitação $(360 \mathrm{~nm} / 40 \mathrm{~nm})$ e o filtro de emissão band pass (BP 470/40 nm) para visualização do núcleo corado pelo Hoescht (fluorescência em azul). Já para visualizar a marcação proveniente dos QDs foi utilizado o filtro de excitação (BP 560/40 nm) e filtro de emissão em (BP 645/75 nm).

A fim de confirmar a especificidade e eficiência do conjugado em se ligar aos receptores de folato, foram realizados ensaios de saturação, adicionando 15 vezes mais de AF do que foi usado no conjugado, a fim de ocupar os receptores de folato nas células HeLa. Para esse ensaio, os poços contendo células foram lavados com PBS, em seguida, foi adicionado PBS $1 \mathrm{X}$ e ácido fólico 1:1 $(\mathrm{v} / \mathrm{v})$, e deixado na estufa incubando por $30 \mathrm{~min}$. Por fim, foi adicionado o conjugado QD-AF na proporção 1:2 v/v e a incubação se procedeu por mais $40 \mathrm{~min}$. Após o tempo de incubação e lavagem das amostras com PBS, as células foram analisadas através de microscopia de fluorescência.

\section{RESULTADOS E DISCUSSÃO}

Caracterização óptica dos QDs e conjugados QDs-AF

$O$ espectro de absorção indicou que os QDs apresentaram um primeiro máximo em $569 \mathrm{~nm}$, como pode ser observado na Figura 1A. Através do comprimento de onda e absorbância do primeiro máximo foi possível estimar o diâmetro médio das nanopartículas em 3,2 nm (DAGTEPE et al., 2007), e utilizando o coeficiente de extinção molar para CdTe proposto por (YU et al., 2003) e a equação de Lambert-Beer foi encontrada uma concentração $\mathrm{ca} .13$ $\mu \mathrm{mol} . \mathrm{L}^{-1} \mathrm{e}$, portanto, $7,8 \times 10^{15}$ partículas $/ \mathrm{mL}$.

De acordo com a emissão, os nanocristais apresentaram máxima emissão na região do laranja em torno de $604 \mathrm{~nm}$ e uma largura à meia altura (FWHM) de aproximadamente $58 \mathrm{~nm}$, indicando uma largura característica de QDs, como representado na Figura 1B.

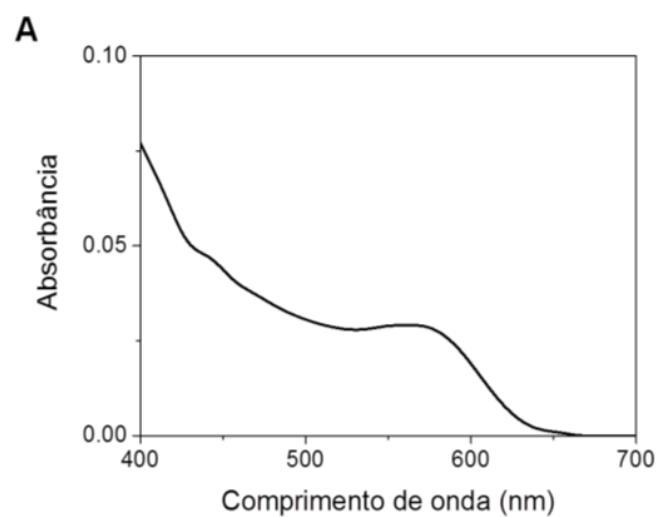

B

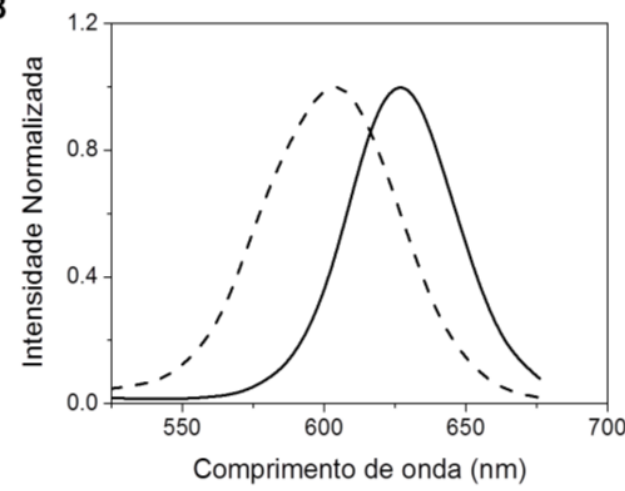

Figura 1. Caracterização óptica dos QDs e conjugados. Em (A) espectro de absorção de QDs (controle), e em (B) emissão dos QDs (controle linha pontilhado) e conjugados (linha cheia), $\lambda_{\text {exc }}=488 \mathrm{~nm}$.

Após cada conjugação foram observados parâmetros físico-químicos das suspensões, tais como boa estabilidade coloidal, manutenção fluorescência com visualização sob luz UV (365 nm) e marcação específica de células. De acordo com os testes realizados, o conjugado correspondente à variação 1 permaneceu fluorescente e sem precipitação, entretanto testes preliminares indicaram a ausência de marcação celular pela microscopia de fluorescência, provavelmente devido à baixa proporção de QDs:AF (1:5). Em seguida, a variação 2 também se manteve fluorescente, mas apresentou precipitação, possivelmente devido à quantidade excessiva de EDC e Sulfo-NHS ou de QDs. A variação 3 apresentou perda da fluorescência e precipitação, devido à baixa concentração do QD e à alta concentração dos agentes de acoplamento. Assim, as concentrações de EDC e Sulfo-NHS da variação 1 foram novamente adotadas e utilizou-se uma concentração de QD intermediária em relação às variações 2 e 3 e também uma maior proporção de QDs:AF. Sendo assim, as conjugações 4 e 5, demostraram ser as mais promissoras, por exibirem parâmetros físico-químicos satisfatórios. Porém, após cerca de 20 dias, o 
conjugado 5 apresentou perda de fluorescência, enquanto o conjugado 4 se manteve estável por pelo menos 3 meses.

Logo, o conjugado correspondente à variação 4 demonstrou ser o mais promissor, por apresentar boa estabilidade (sem precipitação) e boa fluorescência quando visualizado sob luz UV (365 nm). Sendo assim, seguiu-se com a caracterização óptica e a aplicação deste conjugado em sistemas biológicos.

A fim de comparar os efeitos da conjugação sobre as propriedades ópticas dos QDs, foram feitas também caracterizações ópticas dos conjugados (Figura 1B). De acordo com os resultados, não foram observadas mudanças na absorção. Já nos espectros de emissão foi observado um deslocamento para comprimentos de onda maiores (red shift) de aproximadamente $23 \mathrm{~nm}$, podendo ser um indicativo de conjugação (CABRAL FILHO et al., 2016). Suriamoorthy et al. (2010) realizaram trabalho semelhante utilizando QDs de CdTe preparados com ácido tioglicólico (TGA) e conjugados ao AF e os espectros dos conjugados também apresentaram um deslocamento similar.

\section{Marcação por microscopia de fluorescência}

De acordo com a seção anterior, uma vez que o conjugado 4 na proporção 1:25 (QDs-AF) apresentou melhores condições físicoquímicas, tais como boa estabilidade coloidal e alta fluorescência, os resultados a seguir se referem a essa variação.

Os resultados de marcação celular indicaram uma marcação eficiente e específica do receptor de folato em células HeLa. As imagens de fluorescência mostram pequenas e numerosas vesículas no citoplasma celular (Figura 2).
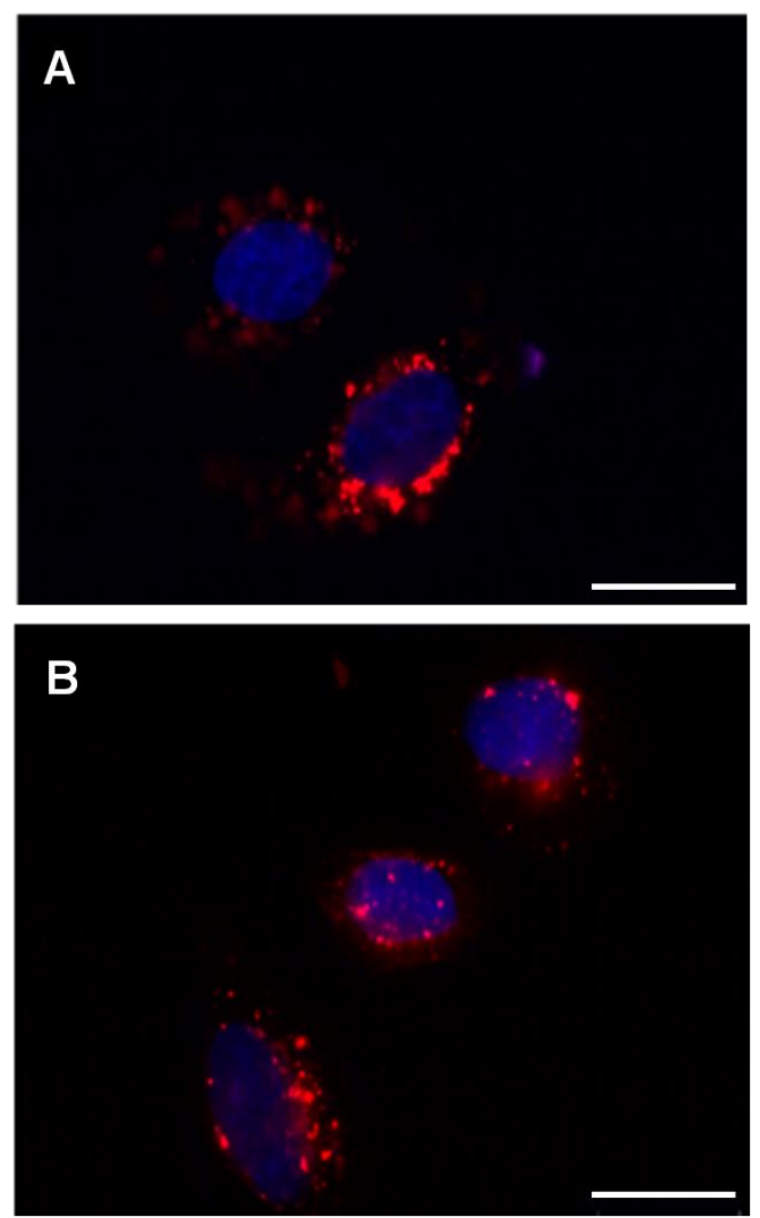

Figura 2. Células HeLa marcadas com QDs-AF. Em (A) e (B) são apresentadas as células marcadas em vermelho pelo conjugado, e em azul núcleos marcados por Hoechst. Barra de escala $=25 \mu \mathrm{m}$

Essa marcação é provavelmente proveniente da interação dos receptores de folatos da membrana celular com o ácido fólico, permitindo assim, a internalização dos sistemas e, através da fluorescência, é possível identificar sua localização (WANG \& LOW, 1998). Além disso, no ensaio de saturação, utilizando excesso de ácido fólico, não foi observada marcação significativa no canal vermelho, demonstrando que a marcação foi específica, via receptor de folato. A utilização do corante de núcleo (em azul Hoechst) ajudou a definir a localização intracelular dos receptores, que provavelmente foram endocitados após a ligação do AF.

Assim como apresentado por Lei et al. (2016), bem como por Wang \& Low (1998), que utilizaram outros tipos de marcadores para identificação do receptor de ácido fólico em células HeLa, nosso trabalho também indicou que estas células apresentam uma grande quantidade de receptores de folato. Portanto, essa célula apresenta-se como um modelo para estudar a eficiência da conjugação de QDs-AF, uma vez que as mesmas apresentam não só receptores de ácido fólico, mas também outros tipos de receptores superexpressos em sua membrana, como os receptores de transferrina (CABRAL FILHO et al., 2016; WANG \& LOW, 1998).

Suriamoorthy et al. (2010), também conjugaram QDs de CdTe ao ácido fólico. Para tanto, utilizaram como funcionalizante/estabilizante o ácido tioglicólico e a conjugação covalente foi propiciada pelo uso de EDC e NHS. Os autores fizeram diálise durante 1 dia para retirar o excesso dos reagentes da conjugação. Para confirmar a conjugação eles utilizaram dois tipos celulares, A549 (linhagem celular de carcinoma de pulmão humano) que não expressa o receptor de folato e as células KB (linhagem celular de carcinoma epidermóide nasofaríngeo), a qual apresenta receptores na membrana. Eles observaram que as células KB apresentam uma elevada marcação pelo conjugado, já a A549 não apresentou marcação, indicando que a fluorescência observada para as células KB ocorreu via receptor. No entanto, o padrão de marcação demonstrado por Suriamoorthy et al. (2010) não apresenta um perfil de endocitose, como sugerido pela literatura (WANG \& LOW, 1998), mas uma marcação de membrana, indicando que a mesma pode não ter sido totalmente especifica ou que as células KB não são tão metabolicamente ativas para a internalização do RF. Diferentemente, o presente trabalho, confirmou, através do ensaio de saturação, a marcação específica desses receptores.

Zhang et al. (2013), desenvolveram conjugados entre QDs de $\mathrm{CdS} / \mathrm{ZnS}$ revestidos com polietileno-imina (PEI) e ácido fólico através de conjugação por adsorção utilizando células HeLa, além de outras linhagens como a HepG2 (carcinoma hepático humano) e A549. Os autores indicaram que as células HeLa e HepG2 apresentaram receptores de ácido fólico, sendo que as células HeLa apresentaram uma expressão de RF levemente maior, tendo um percentual de $86 \%$ de células marcadas, contra $80 \%$ da HepG2. Já as células A549, não apresentaram marcação, por não apresentarem o RF expresso na membrana.

Assim, este presente trabalho apresentou um método simples e eficiente de conjugação que levou à obtenção de conjugados que apresentaram especificidade e alta fluorescência. Além disso, as células HeLa apresentaram marcação uniforme e típica de endocitose dos RF para o citoplasma. Portanto, esse conjugado mostrou-se eficiente para investigação de receptores de folato, podendo-se ampliar os estudos relacionados à biologia celular do câncer, a fim de entender melhor esta doença, utilizando o RF como alvo.

\section{CONCLUSÕES}

Os conjugados de QDs-AF apresentaram-se como promissores sondas fluorescentes específicas. Além disso, permaneceram estáveis por pelo menos 3 meses. A utilização desses conjugados, pode auxiliar a elucidar processos biológicos relacionados o câncer. A compreensão dos aspectos moleculares e da biologia celular do câncer pode ajudar no desenvolvimento de novas terapias mais eficazes para esta doença, tais como àquelas que visam os receptores de folato como uma via de entrada específica e eficiente para drogas quimioterápicas. 


\section{REFERÊNCIAS}

CABRAL FILHO, P. E. et al. CdTe quantum dots as fluorescent probes to study transferrin receptors in glioblastoma cells. Biochimica et Biophysica Acta, v. 1860, n. 1, p. 28-35, 2016.

CHEUNG, R. H. F. et al. Investigation of folic acid stability in fortified instant noodles by use of capillary electrophoresis and reversed-phase high performance liquid chromatography. Journal of Chromatography A, v. 1213, p. 93-99, 2008.

CHEN, C. et al. Structural basis for molecular recognition of folic acid by folate receptors. Nature, v. 500, p. 486-489, 2013.

DAGTEPE, P. et al. Quantized growth of CdTe quantum dots; observation of magic-sized CdTe quantum dots. The Journal of Physical Chemistry C, v. 111(41), p. 14977-14983, 2009.

ESTEVE-TURRILLAS, F. A.; ABAD-FUENTES, A. Applications of quantum dots as probes in immunosensing of small-sized analytes. Biosensors and Bioelectronics, v. 41, p. 12-29, 2013.

KAIRDOLF, B. A et al. Semiconductor quantum dots for bioimaging and biodiagnostic applications. Annual Review of Analytical Chemistry, v. 6, p. 143-162, 2013.

LEI, D. et al. Non-covalent decoration of carbon dots with folic acid via a polymer-assisted strategy for fast and targeted cancer cell fluorescence imaging. Sensors and Actuators B: Chemical, v. 230, p. 714-720, 2016.

SURIAMOORTHY, P. et al. Folic acid-CdTe quantum dots conjugates and their applications for cancer cell targeting. Cancer Nano, v. 1, p. 19-28, 2010.

WANG, S.; LOW, P. S. Folate-mediated targeting of antineoplastic drugs, imaging agents, and nucleic acids to cancer cells. Journal of Controlled Release, v. 53, p. 39-48, 1998.

$\mathrm{YU}, \mathrm{W}$. W. et al. Experimental determination of the extinction coefficient of CdTe, CdSe , and CdS nanocrystals. Chem. Mater, v. 125, n. 17, p. 2854-2860, 2003.

ZHANG, Y. et al. Self-assembly of folate onto polyethyleneiminecoated $\mathrm{CdS} / \mathrm{ZnS}$ quantum dots for targeted turn-on fluorescence imaging of folate receptor overexpressed cancer cells. Anal Chem, China, v. 85, n. 1, p. 228-234, 2013. 